\title{
Effects of leukemia inhibitory factor on 3T3-L1 adipocytes
}

\author{
Jessica C Hogan and Jacqueline M Stephens \\ Department of Biological Sciences, 202 Life Sciences Building, Louisiana State University, Baton Rouge, Louisiana 70803, USA \\ (Requests for offprints should be addressed to J M Stephens; Email: jsteph1@|su.edu)
}

\begin{abstract}
Leukemia inhibitory factor (LIF) is a member of the gp130 cytokine family and signals through the receptor complex of gp130 and the LIF receptor (LIFR) to activate the JAK/STAT signaling cascade. Since LIF activates STATs 1 and 3 in adipocytes, we examined the effects of LIF on 3T3-L1 adipocytes. Our studies clearly demonstrate that LIF treatment had minimal effects on adipocyte differentiation as judged by marker gene expression, but did inhibit triacylglyceride (TAG) accumulation during adipogenesis. Acute treatment with LIF resulted in increased expression of suppressors of cytokine signaling-3 (SOCS3) and CCAAT/enhancer-binding protein- $\delta$ $(\mathrm{C} / \mathrm{EBP} \delta)$ mRNA in 3T3-L1 adipocytes. Moreover, the upregulation of $\mathrm{C} / \mathrm{EBP} \delta$ correlated with binding to three sites in the $\mathrm{C} / \mathrm{EBP} \delta$ promoter by LIF-activated protein

complexes that contained STAT1 and not STAT3. Chronic treatment with LIF resulted in decreased protein levels of sterol regulatory element binding protein-1 (SREBP1) and fatty acid synthase (FAS), but had no effect on the expression of other adipocyte marker proteins or on TAG levels in mature 3T3-L1 adipocytes. LIF had a small effect on insulin-stimulated glucose uptake in 3T3-L1 adipocytes, but did not cause insulin resistance following chronic treatment. These findings indicate that LIF has similar and distinct effects in comparison with the effects of other gp130 cytokines on cultured fat cells. In summary, our results support a role for LIF in the regulation of proteins involved in lipid synthesis and in the modulation of signal transduction pathways in 3T3-L1 adipocytes.

Journal of Endocrinology (2005) 185, 485-496
\end{abstract}

\section{Introduction}

Leukemia inhibitory factor (LIF) is a member of the gp130 cytokine family, cytokines which are unrelated by sequence, but are structurally similar and share a common receptor, gp130 (Robinson et al. 1994, Kishimoto et al. 1995). LIF has pleiotropic actions which include maintaining totipotency of embryonic stem cells (Williams et al. 1988), enhancing survival of peripheral neurons (Murphy et al. 1991) and oligodendrocytes (Butzkueven et al. 2002), and promoting bone formation (Dazai et al. 2000). LIF has also been demonstrated to have multiple effects on adipocytes and adipose tissue. Initially, LIF was characterized as an inducer of cachetic weight loss in mice engrafted with a melanoma cell line that overproduces LIF (Mori et al. 1989). Subsequently, LIF was found to inhibit lipoprotein lipase (LPL) expression and activity in 3T3-L1 and 3T3-F442A adipocytes, without affecting the rate of lipogenesis (Marshall et al. 1994). In addition, adipogenic effects of LIF have been indicated by enhanced activity of glycerol-phosphate dehydrogenase and accumulation of lipid in Ob1771 cells during adipogenesis (Aubert et al. 1999). However, other findings have shown that LIF prevents adipogenesis in bone marrow stromal cells (Gimble et al. 1994) and in 3T3-L1 cells (Ohsumi et al. 1994). Thus, it is likely that the effects of LIF on adipocytes vary with the developmental stage of the cells or tissue.

Cytokines in the gp130 family exhibit functional redundancy as they signal through shared receptor components (Kishimoto et al. 1995). Ciliary neurotropic factor (CNTF), oncostatin M, cardiotropin-1 (CT-1), and LIF bind the LIF receptor (LIFR), in addition to the common receptor, gp130 (Baumann et al. 1993, Wollert et al. 1996). Oligomerization of LIFR and gp130 activates the associated JAK kinase, which phosphorylates tyrosine moieties on the cytoplasmic tail of the receptor. The phosphorylated tyrosines serve as docking sites for signal transducers and activators of transcription (STATs) 1 and 3, which then become phosphorylated, dissociate and form dimers. The STAT dimers immediately translocate to the nucleus to regulate expression of target genes.

Recent work in our laboratory has examined the effects of two other gp130 cytokines, CNTF and CT-1, on adipocytes (Zvonic et al. 2003, 2004). CNTF increased expression and activation of insulin signaling molecules in 3T3-L1 adipocytes, but decreased expression of fatty acid synthase (FAS) and sterol regulatory element binding protein-1 (SREBP1). Like CNTF, CT-1 decreased expression of FAS protein but also decreased expression of insulin receptor substrate-1 (IRS-1) in 3T3-L1 adipocytes, indicating both overlapping and divergent effects of gp130 
cytokines on adipocytes. To further elucidate the role of gp130 cytokines on adipocytes, we have investigated the action of LIF on 3T3-L1 adipocytes. As previously observed with CT-1 and CNTF, LIF neither promoted nor attenuated adipogenesis, in contrast to previous findings for LIF (Gimble et al. 1994, Aubert et al. 1999). We have also shown that FAS and SREBP1 protein levels decreased after a chronic treatment with LIF. In addition, both suppressors of cytokine signaling-3 (SOCS3) and CCAAT/enhancer-binding protein $-\delta(\mathrm{C} / \mathrm{EBP} \delta) \mathrm{mRNA}$ were rapidly induced following treatment of 3T3-L1 adipocytes with LIF. We identified three STAT1 binding sites in the $\mathrm{C} / \mathrm{EBP} \delta$ promoter at positions -696 to $-679,-780$ to -763 , and -1491 to -1475 . Unlike other gp130 cytokines, LIF had no effect on basal or insulin-stimulated glucose uptake, or on the expression of the insulin responsive glucose transporter GLUT4. In summary, our results demonstrate novel and specific effects of LIF on 3T3-L1 adipocytes, suggesting a role for LIF as a regulator of lipid synthesis and an effector of signal transduction in fat cells.

\section{Materials and Methods}

\section{Materials}

Dulbecco's modified Eagle's medium (DMEM), fetal bovine serum (FBS), and leukemia inhibitory factor (LIF) were purchased from Invitrogen. Murine interferon- $\gamma$ (IFN $\gamma$ ) was purchased from Boehringer Mannheim. Bovine serum and growth hormone $(\mathrm{GH})$ were purchased from Sigma. Foxo1, STAT1, STAT3, and highly phospho-specific STAT5 $\left(\right.$ Tyr $\left.^{649}\right)$ antibodies were purchased from Upstate Biotechnology (Waltham, MA, USA); STAT3, STAT5A, peroxisome proliferator activated receptor- $\gamma(\operatorname{PPAR} \gamma)$, and SREBP1 antibodies were purchased from Santa Cruz (Santa Cruz, CA, USA); STAT3, highly phospho-specific STAT3 (Tyr $\left.{ }^{705}\right)$ antibody and FAS antibody were purchased from BD Transduction Laboratories (San Jose, CA, USA). LPL antibody was purchased from Research Diagnostics, Inc. (Flanders, NJ, USA), and highly phospho-specific STAT1 $\left(\mathrm{Tyr}^{701}\right.$ ) was purchased from Biosource (Camarillo, CA, USA). $\left[\alpha-{ }^{32} \mathrm{P}\right] \mathrm{dCTP}$ and $\left[\alpha_{-}{ }^{32} \mathrm{P}\right] \mathrm{dATP}$ were both purchased from Perkin-Elmer (Shelton, CT, USA) and Amersham Biosciences. Deoxynucleotide thymine triphosphate, dATP, and dGTP were purchased from Amersham Biosciences. DNase polymerase I large (Klenow) fragment was purchased from Promega.

\section{Cell culture}

Murine 3T3-L1 preadipocytes were plated and grown to 2 days post-confluence in DMEM containing 10\% bovine serum. Medium was changed every $48 \mathrm{~h}$. Cells were induced to differentiate by changing the medium to DMEM containing 10\% FBS, $0.5 \mathrm{mM}$ 3-isobutylmethylxanthine, $1 \mu \mathrm{M}$ dexamethasone, and $1.7 \mu \mathrm{M}$ insulin (MDI). After $48 \mathrm{~h}$, this medium was replaced with DMEM supplemented with 10\% FBS, and the cells were maintained in this medium until utilized for experimentation.

\section{Preparation of whole cell extracts}

Cell monolayers were rinsed with PBS and then harvested in a nondenaturing buffer containing $10 \mathrm{mM}$ Tris $(\mathrm{pH}$ 7·4), $150 \mathrm{mM} \mathrm{NaCl}, 1 \mathrm{mM}$ EGTA, $1 \mathrm{mM}$ EDTA, $1 \%$ Triton X-100, 0.5\% Nonidet P-40, $1 \mu \mathrm{M}$ phenylmethylsulfonyl fluoride, $1 \mu \mathrm{M}$ pepstatin, 50 trypsin inhibitory milliunits of aprotinin, $10 \mu \mathrm{M}$ leupeptin, and $2 \mathrm{mM}$ sodium vanadate. Samples were extracted for $30 \mathrm{~min}$ on ice and centrifuged at 15000 r.p.m. at $4{ }^{\circ} \mathrm{C}$ for $15 \mathrm{~min}$. Supernatants containing whole cell extracts were analyzed for protein content by BCA analysis (Pierce) according to the manufacturer's instructions.

\section{Gel electrophoresis and immunoblotting}

Proteins were separated in $7 \cdot 5 \%$ polyacrylamide (National Diagnostics, Atlanta, GA, USA) gels containing sodium dodecyl sulfate (SDS) according to the method of Laemmli (1970) and transferred to nitrocellulose (Bio-Rad) in $25 \mathrm{mM}$ Tris, $192 \mathrm{mM}$ glycine, and 20\% methanol. Following transfer, the membrane was blocked in $4 \%$ milk overnight at $4{ }^{\circ} \mathrm{C}$. Results were visualized with horseradish peroxidase (HRP)-conjugated secondary antibodies (Jackson ImmunoResearch Laboratories, West Grave, PA, USA) and enhanced chemiluminescence (Pierce Biotechnology, Rockford, IL, USA).

\section{Determination of 2-deoxyglucose}

The assay of $2-\left[{ }^{3} \mathrm{H}\right]$ deoxyglucose was performed as previously described (Stephens \& Pekala 1991). Briefly, mature 3T3-L1 adipocytes were serum deprived for $4 \mathrm{~h}$ and then incubated in the presence or absence of insulin $(44 \mathrm{nM})$ for $10 \mathrm{~min}$. Glucose uptake was initiated by addition of $2-\left[{ }^{3} \mathrm{H}\right]$ deoxyglucose at a concentration of $0 \cdot 1 \mathrm{mM}$ 2-deoxyglucose in $1 \mu \mathrm{Ci} 2-\left[{ }^{3} \mathrm{H}\right]$ deoxyglucose in Krebs-Ringer-Hepes buffer and incubated for $3 \mathrm{~min}$ at room temperature. Glucose uptake is reported as $\left[{ }^{3} \mathrm{H}\right]$ radioactivity, corrected for nonspecific diffusion $(5 \mu \mathrm{M}$ cytochalasin B) and normalized to total protein content as determined by BCA analysis. Uptake measurements were performed in triplicate under conditions where hexose uptake was linear.

\section{$R N A$ analysis}

Total RNA was isolated from cell monolayers with Trizol (Invitrogen) according to the manufacturer's instructions 
with minor modifications. For Northern blot analysis, $15 \mu \mathrm{g}$ total RNA were denatured in formamide and electrophoresed through a formaldehyde/agarose gel. The RNA was transferred to Zeta Probe-GT (Bio-Rad), cross-linked, hybridized, and washed as previously described (Stephens \& Pekala 1992). Strippable probes were labeled by random priming using the Klenow fragment and $\left[\alpha_{-}{ }^{32} \mathrm{P}\right] \mathrm{dATP}$ using Strip-EZ DNA (Ambion, Austin, TX, USA) according to manufacturer's instructions.

\section{Electrophoretic mobility shift analysis (EMSA)}

Double-stranded oligonucleotides were annealed by heating single-stranded $5^{\prime}$ and $3^{\prime}$ oligonucleotides in a boiling water bath and gradually cooling to room temperature. The $4 \mu \mathrm{g}$ of double-stranded oligonucleotides were $5^{\prime}$-end labeled with $20 \mu \mathrm{Ci}\left[{ }^{32} \mathrm{P}\right](400-800 \mathrm{Ci} / \mathrm{mmol}) \mathrm{dCTP}$ and with $1 \mu \mathrm{l}$ each of $5 \mathrm{mM}$ dATP, dTTP, and dGTP with Klenow fragment. The end-labeling reaction was incubated for $15 \mathrm{~min}$ at $30^{\circ} \mathrm{C}$ and was stopped by adding $1 \mu \mathrm{l}$ 0.5 M EDTA. End-labeled oligonucleotides were purified using a Microspin G-25 column, according to the manufacturer's instructions (Amersham Biosciences). Specific activity of the oligonucleotides was determined by scintillation counting. Nuclear extracts were incubated with the end-labeled oligonucleotides $(50000$ c.p.m./ $\mu$ l) for $30 \mathrm{~min}$ on ice. The samples were loaded into a pre-run $\left(1 \mathrm{~h}, 100 \mathrm{~V}\right.$ at $\left.4{ }^{\circ} \mathrm{C}\right) 6 \%$ acrylamide/bisacrylamide TBE gel containing $90 \mathrm{mM}$ Tris, $90 \mathrm{mM}$ boric acid, and $2 \mathrm{mM}$ EDTA, pH 8.0. For supershift analysis, nuclear extracts were preincubated with $4 \mu \mathrm{g}$ antibody for $1 \mathrm{~h}$ at room temperature. The gels were run at $20 \mathrm{~mA}$ for approximately $2 \mathrm{~h}$. The gels were dried at $80{ }^{\circ} \mathrm{C}$ for $1 \mathrm{~h}$ under a vacuum and then exposed to Kodak BioMax MS film with a Kodak BioMax high energy intensifying screen.

\section{Triglyceride assay}

Cell monolayers were washed with PBS, harvested in a buffer containing $2 \mathrm{M} \mathrm{NaCl}, 2 \mathrm{mM}$ EDTA, $50 \mathrm{mM}$ sodium phosphate, $\mathrm{pH} \quad 7 \cdot 4$ and then sonicated to homogenize the cell suspension. Ten microliters of the lysate were mixed with $10 \mu \mathrm{l}$ tert-butyl alcohol and $5 \mu \mathrm{l}$ of a Triton X-100/methyl alcohol mixture $(1: 1 \mathrm{vol} / \mathrm{vol})$, and were then assayed for triglyceride content using a serum triglyceride determination kit according to the manufacturer's instructions (Sigma). Triglyceride levels were normalized to protein content by BCA (Pierce). Each treatment condition was performed in triplicate and each sample was analyzed twice.

\section{Statistical analysis}

The statistical analyses of the data were performed using ANOVA and the post hoc Scheffé F-test.

\section{Results}

To determine if LIF treatment could modulate adipogenesis, 3T3-L1 preadipocytes were induced to differentiate in the presence or absence of exogenously added LIF. The cells were exposed to LIF $(0 \cdot 5 \mathrm{nM})$ for the entire course of differentiation with a fresh bolus of LIF added at the time of induction and every $24 \mathrm{~h}$ after that. Whole cell extracts were harvested at the time points indicated in Fig. 1 and were analyzed by Western blotting. Adipogenesis was assessed by induction of $\operatorname{PPAR} \gamma, \mathrm{C} / \mathrm{EBP} \alpha$, fatty acid transport protein-4 (FATP4), STAT5A, FAS and adiponectin proteins. Although LIF attenuated the induction of PPAR $\gamma, \mathrm{C} / \mathrm{EBP} \alpha$, and FAS at $48 \mathrm{~h}$ and/or $72 \mathrm{~h}$, LIF did not affect the overall expression of these markers of adipogenesis at $120 \mathrm{~h}$. The induction in STAT5A expression was unaffected by the presence of LIF. The induction of adiponectin was decreased at $96 \mathrm{~h}$, but present at similar levels at $120 \mathrm{~h}$. The expression of STAT3 does not change during adipogenesis (Stewart et al. 1999) and is shown as a loading control (Fig. 1). Phosphorylation of STAT3 was detected in preadipocytes following $15 \mathrm{~min}$ stimulation with LIF. A longer exposure of the film detected a low level of STAT3 phosphorylation through the course of differentiation.

Since LIF is a potent activator of STATs 1 and 3 in 3T3-L1 cells (Stephens et al. 1998) we examined the action of LIF on mature adipocytes. Whole cells extracts were collected from fully differentiated 3T3-L1 adipocytes that were treated with LIF for the various times indicated in Fig. 2. Although the phosphorylation of STATs 1 and 3 was detected at 15 and $45 \mathrm{~min}$ of stimulation, there were no changes in the level of PPAR $\gamma$, Foxo1, SREBP1, FAS, or acetyl CoA carboxylase (ACC) proteins during the time course (Fig. 2). Therefore, we investigated the effect of a chronic LIF treatment on 3T3-L1 adipocytes. Fully differentiated adipocytes were stimulated with LIF for the times indicated in Fig. 3, with a fresh bolus of LIF added every $24 \mathrm{~h}$. Chronic LIF treatment resulted in decreased protein levels of FAS and SREBP1 at $120 \mathrm{~h}$, but the levels for Foxo1, PPAR $\gamma$, LPL and ACC were unchanged. Efficacy of LIF treatment is shown by the phosphorylation of STAT3 during the time course, and positive controls for activation of STATs 1,3 and 5 are shown with extracts from 3T3-L1 adipocytes stimulated for $15 \mathrm{~min}$ with IFN $\gamma$, LIF and GH respectively.

Since other gp130 cytokines have been reported to have effects on insulin signaling and glucose uptake, we investigated the ability of LIF to regulate glucose uptake in 3T3-L1 adipocytes. As shown in Fig. 4A, mature 3T3-L1 adipocytes were pretreated with LIF for $30 \mathrm{~min}, 48 \mathrm{~h}$ or $96 \mathrm{~h}$. Adipocytes were stimulated with insulin for $15 \mathrm{~min}$ and assayed for uptake of $2-\left[{ }^{3} \mathrm{H}\right]$ deoxyglucose. As shown in Fig. 4A, insulin treatment induced an approximately fourfold increase in glucose uptake for all time points (ANOVA F $(7,16)=123 \cdot 37, P=1 \cdot 02 \mathrm{E}-12$; Scheffé's test). 


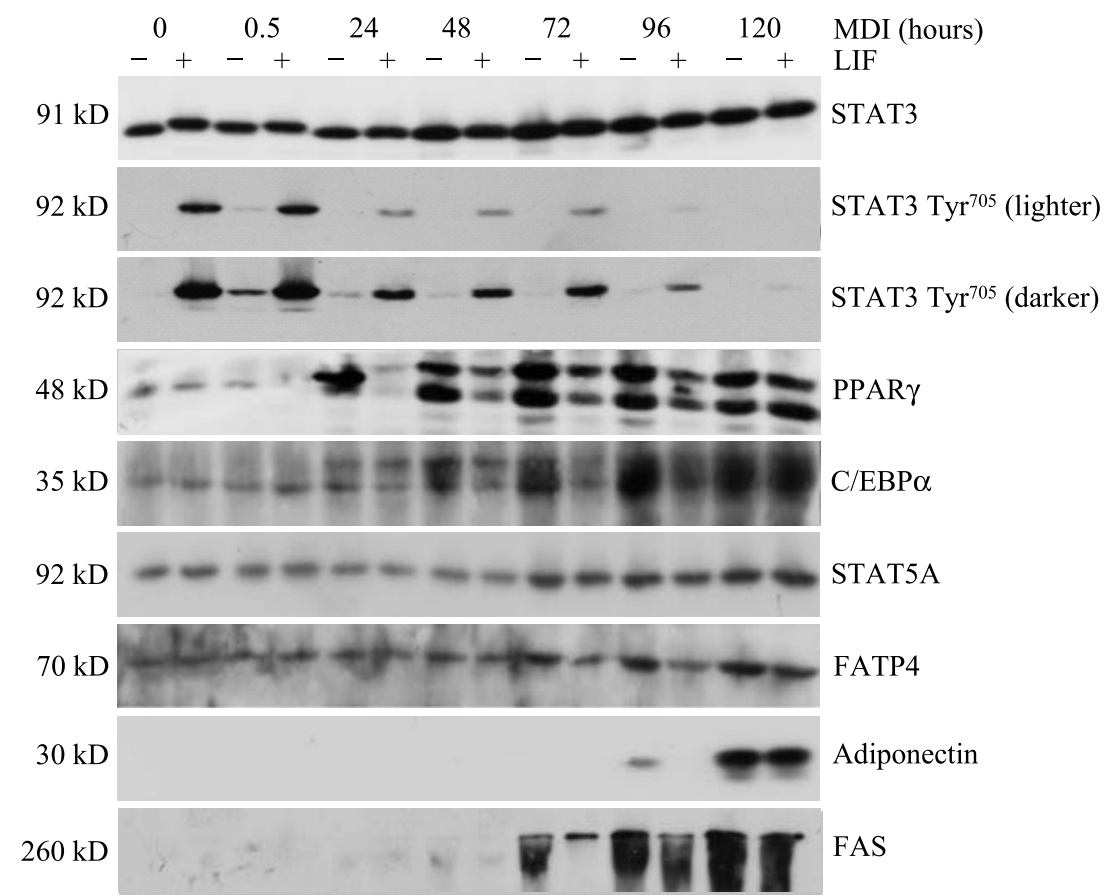

Figure 1 LIF attenuates the differentiation of 3T3-L1 adipocytes. Whole cell extracts were prepared from 3T3-L1 preadipocytes or 3T3-L1 cells induced to differentiate in the presence $(+)$ or absence $(-)$ of LIF $(0.5 \mathrm{nM})$. Media samples were also collected for detection of adiponectin. Cells were treated every $24 \mathrm{~h}$ with a fresh bolus of LIF. Seventy-five micrograms of each sample were separated by SDS-PAGE, transferred to nitrocellulose, and subjected to Western blot analysis. The detection system was HRP-conjugated secondary antibodies and enhanced chemiluminescence. This is a representative experiment independently performed three times.

We observed no significant effects of LIF on the levels of insulin-stimulated glucose uptake. Moreover, LIF had no effects on basal glucose uptake. We also examined the effects of LIF on glucose uptake over an acute time course of treatment, as shown in Fig. 4B. We observed an approximately fourfold increase in glucose uptake for all time points (ANOVA F $(9,19)=59 \cdot 72, \quad P=4.93 \mathrm{E}-12$; Scheffe's test). Exposure to LIF for 1 or $4 \mathrm{~h}$ had no effect on insulin-stimulated glucose uptake; however, at $2 \mathrm{~h}$, there was a consistently observed decrease in insulinstimulated glucose uptake, but this was not statistically significant, as shown in Fig. 4B. We observed no significant effects of LIF on basal glucose uptake (Fig. 4B). Furthermore, there were no effects on the level of GLUT4 mRNA over a time course of $24 \mathrm{~h}$ (Fig. 5). We also examined the effects of a $2-\mathrm{h}$ pretreatment with $\mathrm{CT}-1$ on glucose uptake. Basal or insulin-stimulated levels of glucose uptake were not significantly different from control levels (Fig. 4B).

To examine the effects of LIF on the regulation of mRNA for several adipocyte genes, total RNA was collected from fully differentiated 3T3-L1 adipocytes following treatment with LIF for the times indicated in Fig. 5. Although no changes were detected for $\mathrm{C} / \mathrm{EBP} \alpha$,
$\mathrm{C} / \mathrm{EBP} \beta$, or aP2, LIF induced a rapid and transient upregulation of mRNA for SOCS3 and C/EBP $\delta$ within one hour of stimulation. Furthermore, the upregulation of SOCS3 and C/EBP $\delta$ was independent of ERK/MAP kinase activity, as pretreatment with the MEK inhibitor, U0126, did not block the induction by LIF (data not shown). Induction of SOCS3 by gp130 cytokines has been demonstrated in adipocytes (Zvonic et al. 2004) and is well characterized in other cell types (Krebs \& Hilton 2001).

The role of STAT3 in the upregulation of C/EBP $\delta$ has been investigated in other cell types, and evidence indicated that the -115 to -98 site in the C/EBP $\delta$ promoter was bound by STAT3 following stimulation with interleukin (IL)-6 (Yamada et al. 1997, Hutt et al. 2000). Hence, we examined the ability of LIF to induce binding to the -115 to -98 element of the C/EBP $\delta$ promoter. Electromobility shift assay was performed with nuclear extracts from 3T3-L1 adipocytes treated with LIF for $15 \mathrm{~min}$. As shown in Fig. 6, no detectable binding to the -115 to -98 oligonucleotide was observed with LIF treatment, indicating that this site does not contribute to the regulation of C/EBP $\delta$ by LIF in 3T3-L1 adipocytes. Thus, we looked for other possible STAT binding sites in 


\section{LIF}

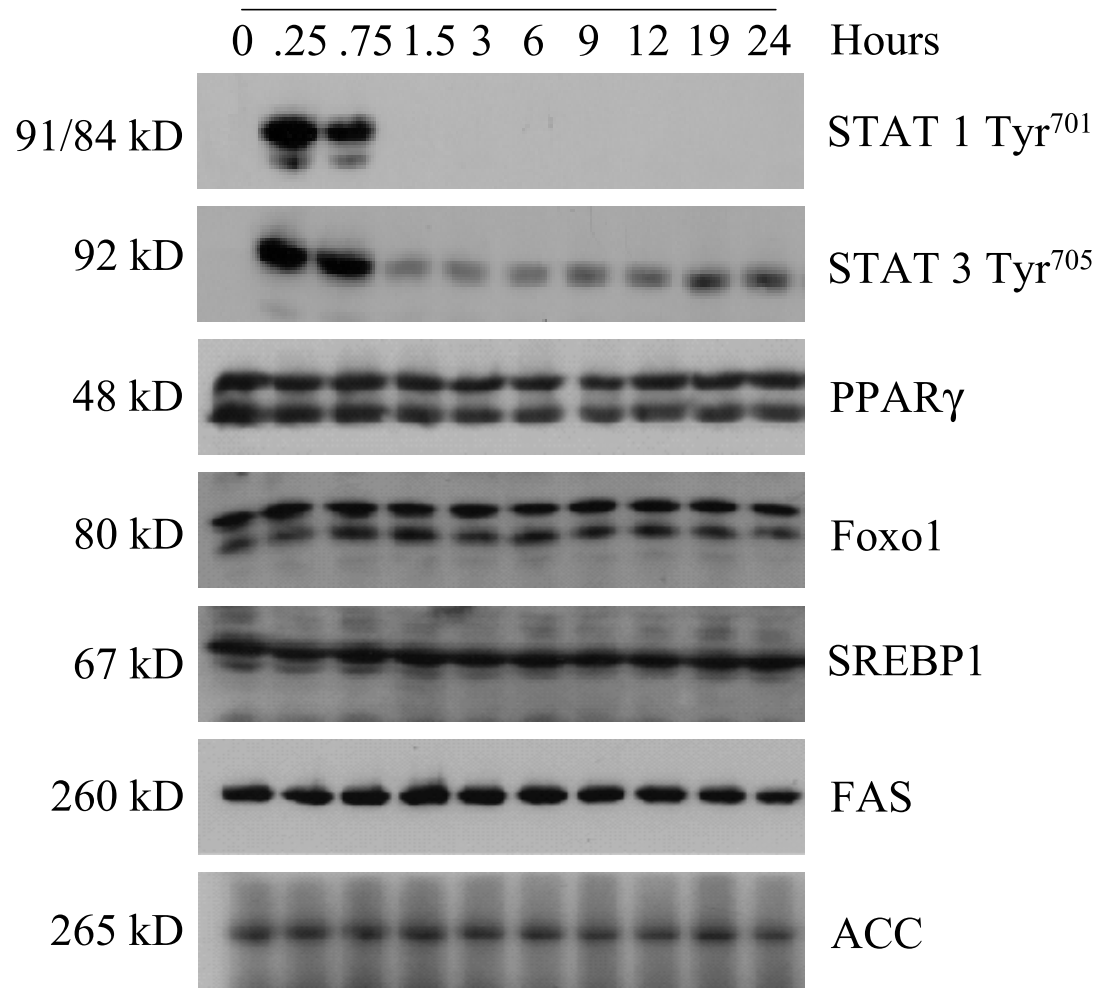

Figure 2 Acute LIF treatment did not affect expression of adipocyte marker proteins in mature 3T3-L1 adipocytes. Fully differentiated 3T3-L1 adipocytes were treated with LIF $(0.5 \mathrm{nM})$ for the times indicated. Seventy-five micrograms protein from whole cell extracts were loaded into the gel for each sample. The samples were subjected to SDS-PAGE, and then were transferred to nitrocellulose for immunoblot analysis. This is a representative experiment independently performed two times.

the $\mathrm{C} / \mathrm{EBP} \delta$ promoter and identified four sites at positions -616 to $-599,-696$ to $-679,-780$ to -763 , and -1491 to -1475 that resembled the consensus STAT recognition sequence TTCNNNGAA (Table 1). Free (on Fig. 6) indicates the presence of the probe alone with no added protein extract to the sample. As shown in Fig. 6, LIF-induced nuclear protein complexes shifted the sites at -696 to $-679,-780$ to -763 , and -1491 to -1475 , but not the -616 to -599 oligonucleotide (data not shown). Cold competition analysis with excess unlabeled oligonucleotides revealed the specificity of these interactions (data not shown). Because LIF is a strong activator of STAT3 (see Figs 2 and 3), we hypothesized that the protein complex contained STAT3. However, supershift analysis using multiple STAT3 antibodies, along with antibodies against STAT1 and STAT5A clearly indicates that the protein complex induced by LIF primarily contains STAT1 (Fig. 7A, panels 1-3, lane 7). As shown in Fig. 7A, no supershift was detected with a STAT5A antibody (lane 8) or with STAT3 antibodies that recognize the carboxy terminus (lane 4), amino acids
1-175 (lane 5), or amino acids 688-722 (lane 6) of STAT3. We also examined the induction of binding by LIF-induced proteins to two oligonucleotides that are routinely used as positive controls for STAT3 binding, the -168 to -148 site from the rat $\alpha_{2}$-macroglobulin $\left(\alpha_{2} \mathrm{M}\right)$ promoter (Hattori et al. 1990) and the m67 oligonucleotide derived from the c-fos -345 to -323 promoter, which strongly binds cytokine-induced protein complexes (Wagner et al. 1990). As shown in Fig. 7A, LIF treatment induced binding to these oligonucleotides (panels 4 and 5 , lane 3). Similar to our findings with the $\mathrm{C} / \mathrm{EBP} \delta$ promoter sites, only STAT1 antibody supershifted the protein complex induced by LIF for both the m67 and $\alpha_{2} \mathrm{M}$ oligonucleotides. To further investigate the activation of STAT3 binding by LIF, we used a longer m67 oligonucleotide for EMSA analysis (Fig. 7B). We detected binding by two protein complexes that were induced by LIF. The weak binding by the protein complex exhibiting slower mobility was blocked by antibodies for STAT3 (lanes 4 and 5). The more prominent protein complex exhibiting faster mobility was supershifted by STAT1 


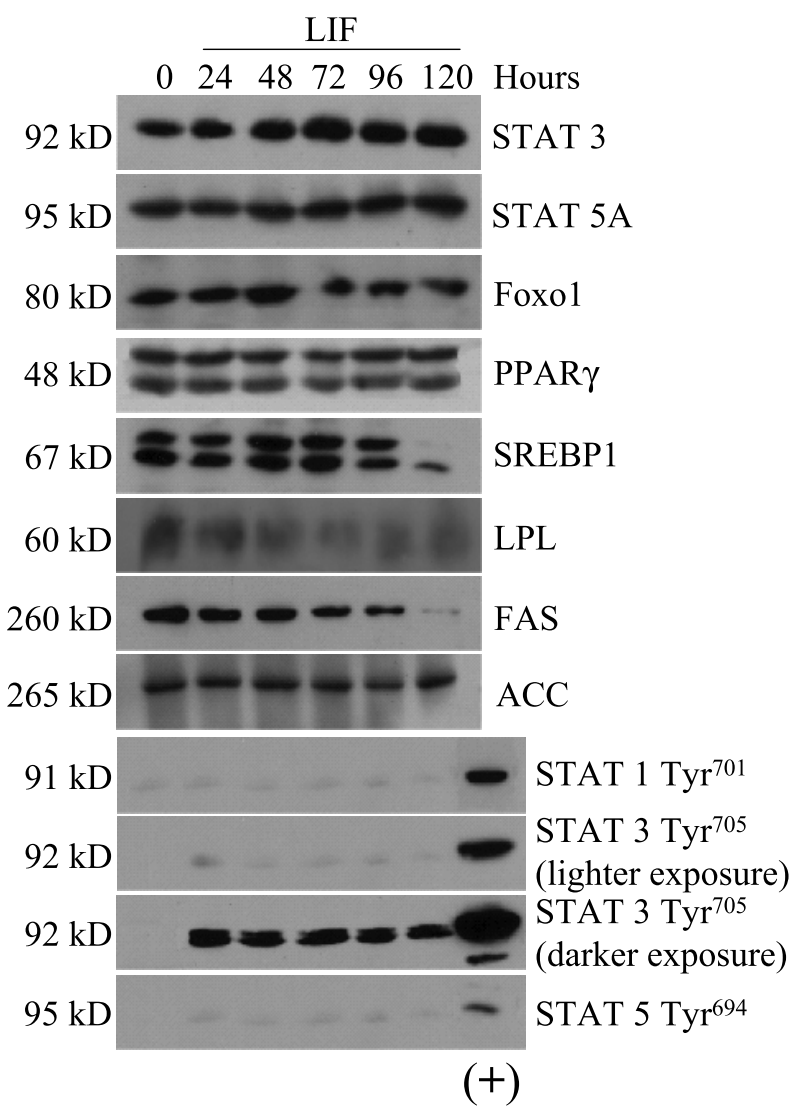

Figure 3 The effect of chronic treatment of LIF on 3T3-L1 adipocytes. Whole cell extracts were prepared from fully differentiated 3T3-L1 adipocytes following treatment with LIF $(0.5 \mathrm{nM})$ for the indicated times. Cells were treated every $24 \mathrm{~h}$ with a fresh bolus of LIF. Seventy-five micrograms of each sample were separated by SDS-PAGE, transferred to nitrocellulose, and subjected to Western blot analysis. (+) indicates a positive control of a 15-min treatment with IFN $\gamma$, LIF and GH for activation of STAT1, STAT3 and STAT5 respectively. This is a representative experiment independently performed two times.

antibody (lane 6). STAT5A antibody was included as a negative control. Thus, although LIF is a potent activator of STAT3, STAT1 appears to preferentially bind under these conditions in 3T3-L1 adipocytes. Furthermore, our supershift analysis suggests that STAT1 contributes to the LIF-induced modulation of $\mathrm{C} / \mathrm{EBP} \delta$ in adipocytes.

Since we observed a delay in the expression of several adipocyte marker proteins during adipogenesis in the presence of LIF, we examined the effect of LIF on the accumulation of triglycerides (TAG) during the differentiation of 3T3-L1 cells. 3T3-L1 preadipocytes were induced to differentiate in the presence or absence of LIF $(0.5 \mathrm{nM})$. A fresh bolus of LIF was added every $24 \mathrm{~h}$. Cells were harvested at the times indicated in Fig. 8A. As shown in Fig. 8A, in the absence of LIF treatment, triglyceride content increased during differentiation (ANOVA $\mathrm{F}$ $(7,16)=28 \cdot 51, P=6 \cdot 88 \mathrm{E}-8$; Scheffe's test). Although the triglyceride content also increased in the LIF-treated cells during adipogenesis, the level of triglycerides in LIFtreated cells at $120 \mathrm{~h}$ was significantly lower than the level observed in the untreated adipocytes (Fig. 8A). We also examined the effect of LIF on triglyceride content in mature adipocytes. Mature 3T3-L1 adipocytes were stimulated with LIF for the various times indicated in Fig. 8B. As shown in Fig. 8B, LIF treatment did not diminish the level of triglyceride in 3T3-L1 adipocytes (ANOVA $\mathrm{F}(5,6)=0 \cdot 30, P=0 \cdot 89$ ).

\section{Discussion}

Recent work from our laboratory has demonstrated that gp130 cytokines, CT-1 and CNTF, have overlapping and divergent effects on the expression and activation of proteins of lipid and glucose metabolism in adipocytes (Zvonic et al. 2003, 2004). The gp130 cytokines activate the JAK/STAT pathway via the gp130 and LIF receptors. Because LIF also signals through gp130 and LIFR, we hypothesized that LIF would regulate adipocyte proteins. Our studies with 3T3-L1 cells have shown that LIF activates STATs 1 and 3 in preadipocytes and mature adipocytes. Because LIFR is expressed more abundantly in preadipocytes (Zvonic et al. 2003), we predicted that LIF would regulate adipogenesis as was previously shown in 3T3-L1 cells (Ohsumi et al. 1994). However, we observed only modest effects of LIF on the in vitro differentiation of 3T3-L1 adipocytes. In another cell line, Ob1771, LIF promotes differentiation (Aubert et al. 1999). Thus, it is possible that this discrepancy is due to differences in commitment to the adipocyte lineage of these two cell lines.

Since adipocytes are responsive to LIF, we studied the effects of this cytokine on fully differentiated adipocytes. Acute treatment did not regulate the expression of several adipocyte proteins, but expression of SOCS3 and C/EBP $\delta$ mRNA was strongly and transiently stimulated by LIF. SOCS3 is a member of the SOCS protein family, which is characterized by the ability to negatively modulate cytokine signaling (Krebs \& Hilton 2001). The induction of SOCS3 expression has been demonstrated by many cytokines, and direct regulation by STAT proteins has been described (Auernhammer et al. 1999). These data are consistent with recent findings from our laboratory that CNTF and CT-1 upregulate SOCS3 mRNA (Zvonic et al. 2004). Interestingly, there is recent evidence that SOCS3 is a regulator of insulin signaling and may cause insulin resistance in adipocytes through its effects on IRS protein expression (Shi et al. 2004). Although we did not observe any significant effects on insulin-stimulated glucose uptake by LIF, the upregulation of SOCS3 by gp130 cytokines is clearly a major component of JAK/STAT signaling in adipocytes. 
A
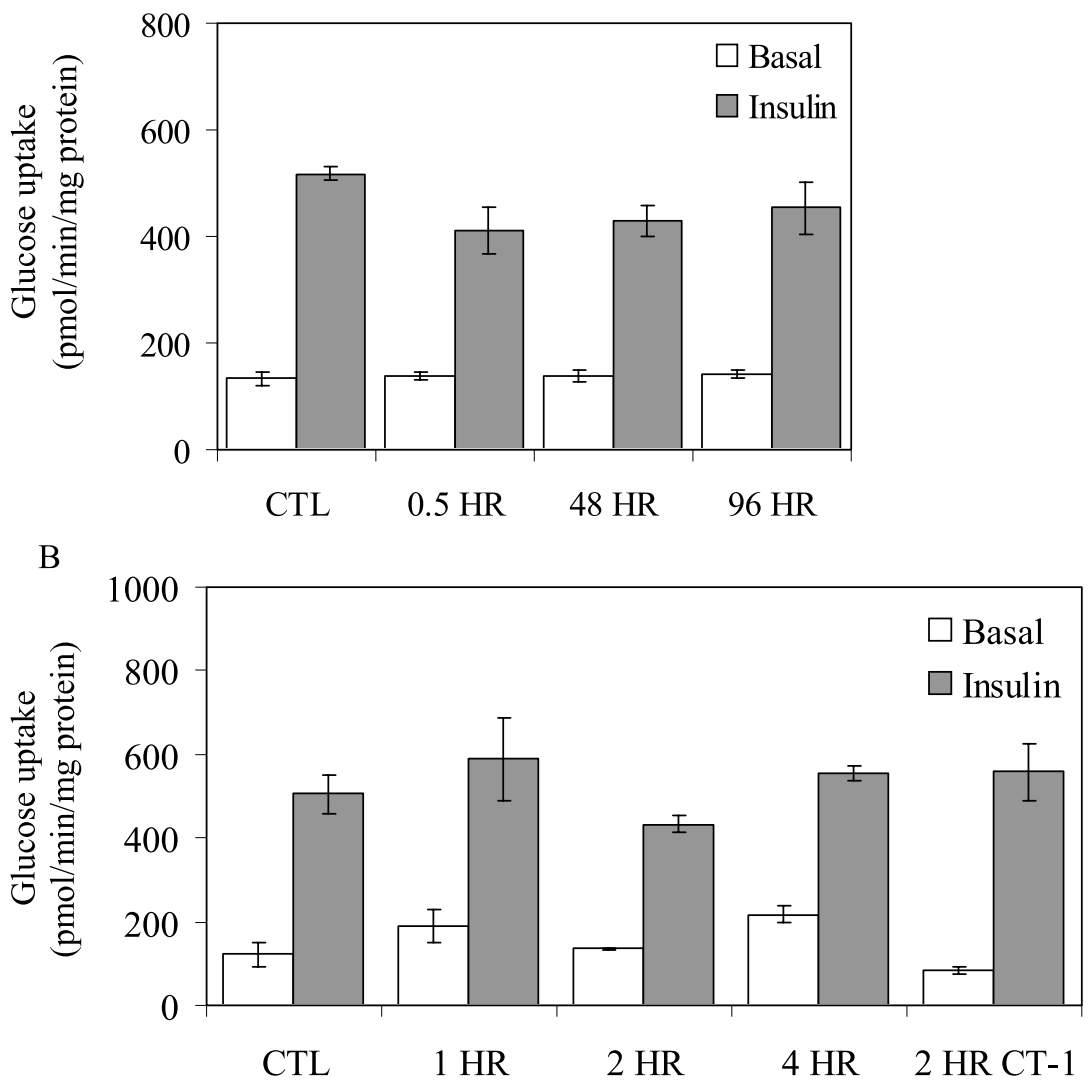

Figure 4 LIF does not affect insulin stimulation of glucose uptake. (A) Fully differentiated 3T3-L1 adipocytes were treated with LIF $(0.5 \mathrm{nM})$ for the times indicated. Cells were treated every $24 \mathrm{~h}$ with a fresh bolus of LIF. Cells were serum deprived for $4 \mathrm{~h}$ and then stimulated with insulin ( $44 \mathrm{nM})$ for $15 \mathrm{~min}$. Glucose uptake was initiated by addition of $2-\left[{ }^{3} \mathrm{H}\right]$ deoxyglucose. Glucose uptake for each time point was measured in triplicate and is given as the mean \pm S.D $(P<0 \cdot 01$; Scheffé's test; ANOVA F $(7,16)=123 \cdot 37$, $P=1 \cdot 02 \mathrm{E}-12$ ). (B) Fully differentiated 3T3-L1 adipocytes were serum deprived for $4 \mathrm{~h}$ and were stimulated with LIF $(0.5 \mathrm{nM})$ for the times indicated. Cells were then stimulated with insulin ( $44 \mathrm{nM}$ ) for $15 \mathrm{~min}$. Glucose uptake was initiated by addition of $2-\left[{ }^{3} \mathrm{H}\right]$ deoxyglucose. Glucose uptake for each time point was measured in triplicate and is given as the mean \pm S.D. $(P<0 \cdot 01$; Scheffé's test; ANOVA F $(9,19)=59 \cdot 72, P=4 \cdot 93 \mathrm{E}-12)$. This is a representative experiment independently performed two times. CTL, control untreated cells. In both (A) and (B) the only significant differences were between basal and insulin-stimulated conditions.

$\mathrm{C} / \mathrm{EBP} \delta$ is a basic-leucine zipper transcription factor with a well-established role in adipogenesis (Darlington et al. 1998), although knock-out studies indicate that $\mathrm{C} / \mathrm{EBP} \delta$ alone is weakly adipogenic (Tanaka et al. 1997). The IL-6 upregulation of $\mathrm{C} / \mathrm{EBP} \delta$ in mammary epithelium (Hutt et al. 2000) and HepG2 cells (Yamada et al. 1997) has been shown to be mediated by the -115 to -98 region of the promoter, but our data indicated that this site was not sensitive to LIF regulation in adipocytes (Fig. 6). However, three other sites at positions -696 to $-679,-780$ to -763 , and -1491 to -1475 were bound by LIF-activated protein complexes which con- tained STAT1 (Fig. 6). Interestingly, the protein complex did not contain STAT3, as we had predicted, since LIF is a more potent activator of STAT3 than of STAT1, as shown in Fig. 2. Moreover, we did not observe STAT3 binding to two oligonucleotides routinely used as positive controls for STAT3 binding, the -168 to -148 site of the rat $\alpha_{2} \mathrm{M}$ promoter (Hattori et al. 1990) and m67 (Wagner et al. 1990). Yet, our supershift analysis revealed that these oligonucleotides were shifted by protein complexes which contained STAT1. Only when we used a long form of the m67 oligonucleotide did we detect a faint band that represented a STAT3 binding site. Our 


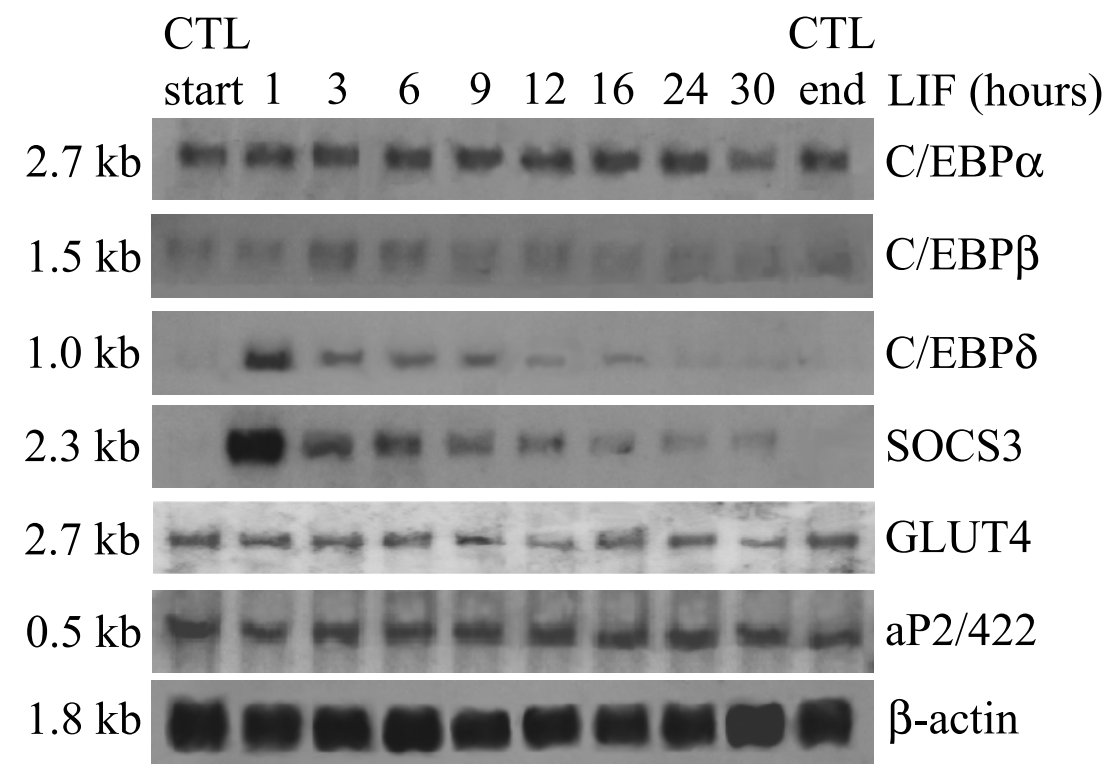

Figure 5 LIF induces the expression of C/EBP $\delta$ and SOCS3 mRNA. Total RNA was isolated from 3T3-L1 adipocytes following treatment with LIF $(0.5 \mathrm{nM})$ for the times indicated above. Untreated cells (CTL) were harvested at the start and end of the time course. Fifteen micrograms total RNA were electrophoresed, transferred to nylon, and subjected to Northern blot analysis with radiolabeled probes for the indicated genes. Hybridization to $\beta$-actin is included as a loading control. This is a representative experiment independently performed two times.

observations strongly suggest that STAT1 preferentially binds under these conditions in 3T3-L1 adipocytes. These results have led us to hypothesize that the three sites in the $\mathrm{C} / \mathrm{EBP} \delta$ promoter confer the LIF response and that binding by STAT1 may mediate the upregulation of $\mathrm{C} / \mathrm{EBP} \delta$ in adipocytes.

The consequences of increased expression of $\mathrm{C} / \mathrm{EBP} \delta$ in mature adipocytes are not known. It has been shown

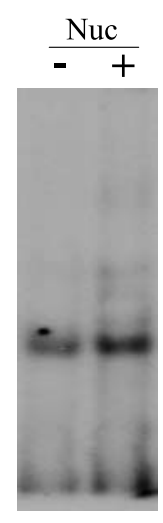

$-1 \overline{15 \text { to }-98}$

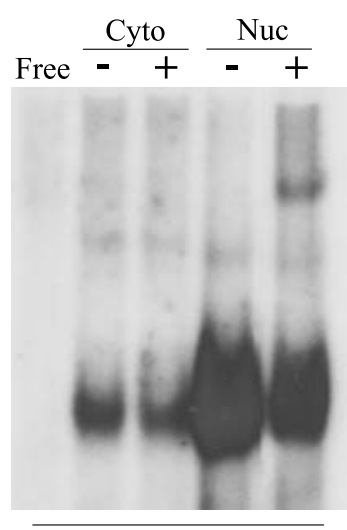

-696 to -679
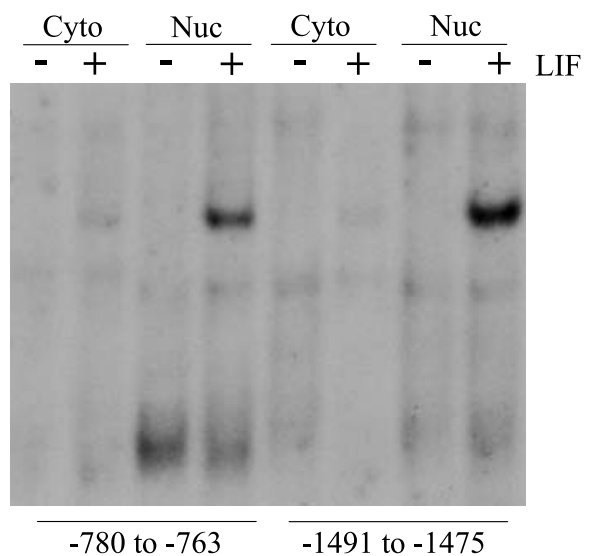

Figure 6 LIF activates binding by protein complexes from the nuclei of 3T3-L1 adipocytes to three sites of the $\mathrm{C} / \mathrm{EBP} \delta$ promoter. Nuclear extracts were prepared from differentiated 3T3-L1 adipocytes that were untreated $(-)$ or treated $(+)$ with LIF for $15 \mathrm{~min}$. For each sample, $10 \mu \mathrm{g}$ protein were incubated with 50000 c.p.m./ml of the indicated ${ }^{32}$ P-labeled probe of the $\mathrm{C} / \mathrm{EBP} \delta$ promoter. Free indicates the presence of the probe alone with no added protein extract to the sample. The protein-DNA complexes were resolved by electromobility shift assay. This is a representative experiment independently performed two times. Nuc, nucleus; Cyto, cytosol. 
Table 1 Potential STAT binding sites in the C/EBP $\delta$ promoter

Position
-115 to -98
-696 to -679
-780 to -763
-1491 to -1475
-168 to $-148 \alpha_{2} \mathrm{M}$
m67
Consensus

\section{Sequence}

TCG TTC CCA GCA GCA AC

AAT TTC AGA ATA ATA TCC

CTT TTC ACG AAT TTT GAA

AT TTC TGG AAA AAT TGA A

TCC TTC TGG GAA TC

CGT TTC CCG TAA ATC CCT CCC

TTC NNN GAA

\section{LIF-responsive}

No

Yes

Yes

Yes

Yes

Yes
$(A)$

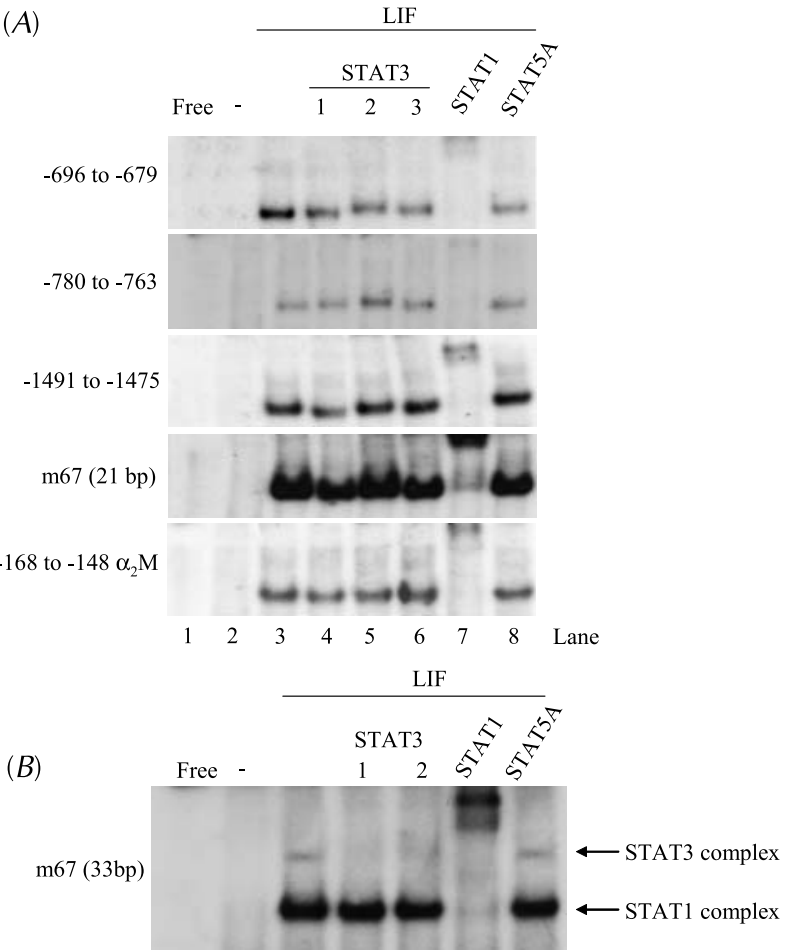

Figure 7 Binding of LIF-activated STAT1, not STAT3, to sites in the $\mathrm{C} / \mathrm{EBP} \delta$ promoter. Nuclear extracts were prepared from fully differentiated 3T3-L1 adipocytes that were untreated $(-)$ or treated with LIF for $15 \mathrm{~min}$. In the top panel of gels (A), the untreated $(-)$ sample is present in lane 2 and the LIF treated samples are present in lanes $3-8$. In the $\mathrm{m} 67$ gel (B), all the samples are LIF treated except the one labeled $(-)$. For each sample, $10 \mu \mathrm{g}$ protein were incubated with 50000 c.p.m./ml of the ${ }^{32}$ P-labeled probe of the C/EBP $\delta$ promoter or of the STAT3 oligonucleotides for $\mathrm{m} 67$ or the -168 to -148 site of the rat $\alpha_{2} M$ promoter. For supershift, samples were preincubated with the indicated antibodies $(4 \mu \mathrm{g})$ : STAT3 1 (Santa Cruz C-20), 2 (BD Transduction Laboratories), 3 (Upstate Biotechnology), STAT1 (Upstate Biotechnology), and STAT5 (Santa Cruz L-20). The protein-DNA complexes were resolved by electromobility shift assay. Free indicates the presence of the probe alone with no added protein extract to the sample. This is a representative experiment independently performed two times. that tumor necrosis factor- $\alpha$ (Kurebayashi et al. 2001), dexamethasone (MacDougald et al. 1994), and insulin (MacDougald et al. 1995) also upregulate $\mathrm{C} / \mathrm{EBP} \delta$ in mature adipocytes in a rapid and transient manner. Interestingly, the lack of effect of LIF on C/EBP $\alpha$ expression suggests that although $\mathrm{C} / \mathrm{EBP} \alpha$ is regulated by $\mathrm{C} / \mathrm{EBP} \delta$ in differentiating adipocytes (Lane et al. 1999), it is not affected by $\mathrm{C} / \mathrm{EBP} \delta$ expression in mature adipocytes. In other cell types, C/EBP $\delta$ negatively regulates the expression of the $\alpha 2$ chain of type I collagen, a critical structural component of the extracellular matrix (Greenwel et al. 2000). C/EBP $\delta$ upregulates expression of IL-6 in astrocytes (Schwaninger et al. 2000), intestinal epithelial cells (Hungness et al. 2002), and osteoblasts (Ruddy et al. 2004); thus, IL-6, an adipokine associated with obesity (Bastard et al. 2000) may be a transcriptional target of $\mathrm{C} / \mathrm{EBP} \delta$ in adipocytes as well. Effects on $\mathrm{C} / \mathrm{EBP} \delta$ targets would likely be transient, since the induction of C/EBP $\delta$ is short-lived (MacDougald et al. 1994). These potential outcomes of increased C/EBP $\delta$ expression give insight into one means by which LIF exerts effects on adipocyte function.

We also examined the effect of a chronic administration of LIF in fully differentiated adipocytes. Both FAS and SREBP1 proteins exhibited decreased expression after $120 \mathrm{~h}$ of LIF stimulation. FAS is the enzyme catalyzing all of the steps in the synthesis of palmitate from acetyl CoA and malonyl, and the level of its expression is coupled to the rate of lipogenesis (Sul \& Wang 1998). SREBP1 is a transcription factor known to modulate genes associated with fat and cholesterol metabolism (Horton et al. 2002), including FAS (Bennett et al. 1995). The decreased expression of SREBP1 and FAS may result in changes in lipid accumulation in adipocytes as a result of prolonged exposure to LIF. Indeed, LIF decreases TAG accumulation during adipogenesis, but has little effect on TAG levels in fully differentiated cells. However since the effects on SREBP and FAS require chronic treatment (5 days), it is highly likely that these effects are indirect.

In the light of recent studies demonstrating upregulation of GLUT4 expression by CNTF (Zvonic et al. 2003) and improved insulin-stimulated glucose uptake by CT-1 (Zvonic et al. 2004), we investigated the ability of LIF to 
A

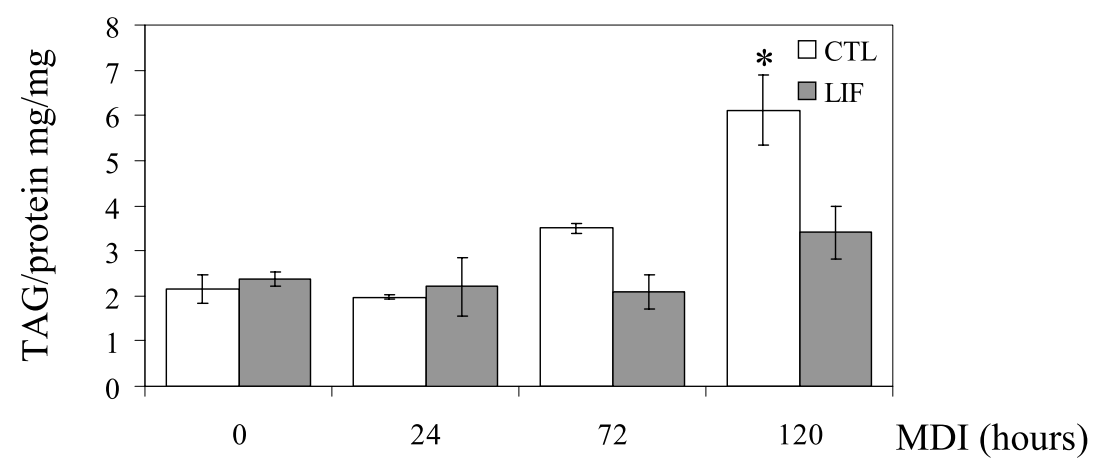

B

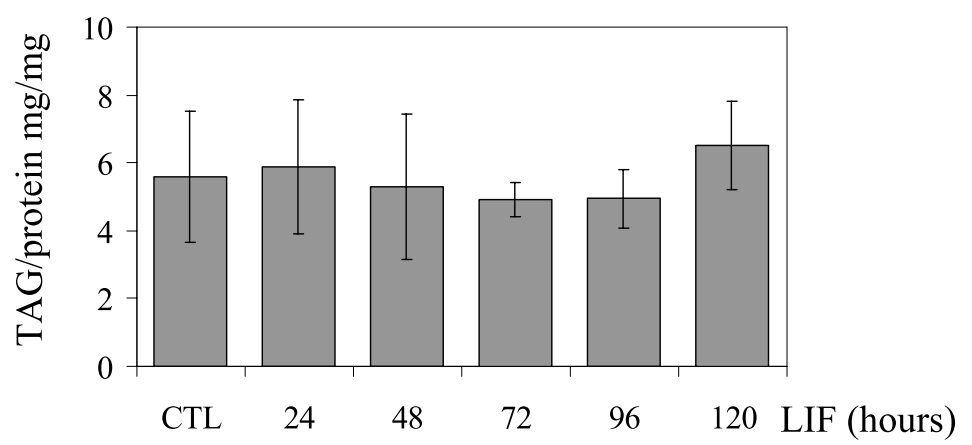

Figure 8 LIF diminishes the accumulation of triglycerides during adipogenesis. (A) 3T3-L1 cells were induced to differentiate in the presence or absence of LIF $(0 \cdot 5 \mathrm{nM})$. Cells were treated every $24 \mathrm{~h}$ with a fresh bolus of LIF. Cells were harvested in $2 \mathrm{M} \mathrm{NaCl}, 2 \mathrm{mM}$ EDTA, $50 \mathrm{mM}$ sodium phosphate, $\mathrm{pH} 7 \cdot 4$. Cell lysates were mixed in an equal volume of tert-butyl alcohol and $\frac{1}{2}$ volume of a 1:1 mixture of Triton X-100 and methyl alcohol. Trigylceride content was measured according to package instructions (Sigma). The triglyceride level for each time point was measured in triplicate, normalized to protein concentration $(\mathrm{mg} / \mathrm{mg})$ and is given as the mean \pm S.D Asterisk indicates statistically significant difference compared with all time points $(P<0 \cdot 01$; Scheffé's test; ANOVA F $(7,16)=28 \cdot 51, P=6 \cdot 88 \mathrm{E}-8)$. (B) Mature 3T3-L1 adipocytes were stimulated with LIF $(0.5 \mathrm{nM})$ for the times indicated and were treated every $24 \mathrm{~h}$ with a fresh bolus of LIF. Triglyceride content was determined as described above (ANOVA $F(5,6)=0 \cdot 30, P=0 \cdot 89$ ). This is a representative experiment independently performed two times.

modulate glucose uptake in adipocytes. Our findings demonstrate that LIF does not substantially affect basal or insulin-stimulated glucose uptake, and does not modulate expression of GLUT4. Thus, LIF likely does not greatly affect glucose disposal in adipose tissue.

In summary, we have demonstrated that LIF activates the JAK/STAT pathway in 3T3-L1 preadipocytes and adipocytes. Although LIF had modest affects on adipogenesis of 3T3-L1 cells as judged by examining numerous fat markers, the presence of LIF during differentiation resulted in a significant decrease in TAG levels. We also demonstrated that LIF increased C/EBP $\delta$ expression after an acute exposure. We have identified three LIF-responsive sites in the $\mathrm{C} / \mathrm{EBP} \delta$ promoter that are distinct from the previously reported STAT3 binding site for IL-6 regulation in mammary epithelial cells (Hutt et al.
2000) and hepatocytes (Yamada et al. 1997). Moreover, these three newly identified and LIF-responsive sites bind STAT1, rather than STAT3. LIF, similar to CT-1 and CNTF, regulated proteins involved in lipid accumulation, SREBP1 and FAS, which may be indicative of a redundant role of gp130 cytokines in the modulation of adipocyte function. However, unlike these cytokines, LIF had no effect on basal or insulin-stimulated glucose uptake. These results were somewhat unexpected, given that all three cytokines signal through the same receptor components. Yet each cytokine activates a unique pattern of STATs in adipocytes. CNTF only activates STAT3 (Zvonic et al. 2003), whereas LIF activates STATs 1 and 3, and CT-1 activates STATs 1, 3 and 5 (Zvonic et al. 2004). Therefore, we predict that the variation in recruitment of these transcription factors mediates the 
nonredundant downstream effects of gp130 cytokines in 3T3-L1 adipocytes. Furthermore, crosstalk with other signaling pathways may contribute to the divergent effects of gp130 cytokines. Current studies are underway to investigate the crosstalk among gp130 cytokines in adipocytes.

\section{Acknowledgements}

We would like to thank James E Baugh Jr for technical assistance with this project.

\section{Funding}

This work was supported by grant R01DK52968-02 from the National Institutes of Health to J M S. The authors declare that there is no conflict of interest that would prejudice the impartiality of this scientific work.

\section{References}

Aubert J, Dessolini S, Belmont N, Li M, McKenzie FR, Staccini L, Villageois P, Barhanin B, Vernallis A, Smith AG, Ailhaud G \& Dani C 1999 Leukemia inhibitory factor and its receptor promote adipocyte differentiation via the mitogen-activated protein kinase cascade. Journal of Biological Chemistry 274 24965-24972.

Auernhammer CJ, Bousquet C \& Melmed S 1999 Autoregulation of pituitary corticotroph SOCS3 expression: characterization of the murine SOCS3 promoter. PNAS 96 6964-6969.

Bastard JP, Jardel C, Bruckert E, Blondy P, Capeau J, Laville M, Vidal H \& Hainque B 2000 Elevated levels of interleukin 6 are reduced in serum and subcutaneous adipose tissue of obese women after weight loss. Journal of Clinical Endocrinology and Metabolism $\mathbf{8 5}$ 3338-3342.

Baumann H, Ziegler SF, Mosley B, Morella KK, Pajovic S \& Gearing DP 1993 Reconstitution of the response to leukemia inhibitory factor, oncostatin $\mathrm{M}$, and ciliary neurotrophic factor in hepatoma cells. Journal of Biological Chemistry 268 8414-8417.

Bennett MK, Lopez JM, Sanchez HB \& Osborne TF 1995 Sterol regulation of fatty acid synthase promoter. Coordinate feedback regulation of two major lipid pathways. Journal of Biological Chemistry $27025578-25583$.

Butzkueven H, Zhang JG, Soilu-Hanninen M, Hochrein H, Chionh F, Shipham KA, Emery B, Turnley AM, Petratos S, Ernst M, Bartlett PF \& Kilpatrick TJ 2002 LIF receptor signaling limits immune-mediated demyelination by enhancing oligodendrocyte survival. Nature Medicine 8 613-619.

Darlington GJ, Ross SE \& MacDougald OA 1998 The role of C/EBP genes in adipocyte differentiation. Journal of Biological Chemistry 273 30057-30060.

Dazai S, Akita S, Hirano A, Rashid MA, Naito S, Akino K \& Fujii T 2000 Leukemia inhibitory factor enhances bone formation in calvarial bone defect. Journal of Craniofacial Surgery 11 513-520.

Gimble JM, Wanker F, Wang CS, Bass H, Wu X, Kelly K, Yancopolous GD \& Hill MR 1994 Regulation of bone marrow stromal cell differentiation by cytokines whose receptors share the gp130 protein. Journal of Cellular Biochemistry 54 122-133.

Greenwel P, Tanaka S, Penkov D, Zhang W, Olive M, Moll J, Vinson C, Di Liberto M \& Ramirez F 2000 Tumor necrosis factor alpha inhibits type I collagen synthesis through repressive CCAAT/enhancer-binding proteins. Molecular and Cellular Biology 20 912-918.

Hattori M, Abraham LJ, Northemann \& Fey GH 1990 Acute-phase reaction induces a specific complex between hepatic nuclear proteins and the interleukin 6 response element of the rat $\alpha_{2}$-macroglobulin gene. PNAS 87 2364-2368.

Horton JD, Goldstein JL \& Brown MS 2002 SREBPs: activators of the complete program of cholesterol and fatty acid synthesis in the liver. Journal of Clinical Investigation 109 1125-1131.

Hungness ES, Luo GJ, Pitts TA, Sun X, Robb BW, Hershko D \& Hasselgren PO 2002 Transcription factors C/EBP-beta and -delta regulate IL-6 production in IL-1 beta-stimulated human enterocytes. Journal of Cell Physiology 192 64-70.

Hutt JA, O'Rourke JP \& DeWille J 2000 Signal transducer and activator of transcription 3 activates CCAAT enhancer-binding protein $\delta$ gene transcription in G0 growth-arrested mouse mammary epithelial cells and in involuting mouse mammary gland. Journal of Biological Chemistry 275 29123-29131.

Kishimoto T, Akira S, Narazaki M \& Taga T 1995 Interleukin-6 family of cytokines and gp130. Blood 86 1243-1254.

Krebs DL \& Hilton DJ 2001 SOCS proteins: negative regulators of cytokine signaling. Stem Cells 19 378-387.

Kurebayashi S, Sumitani S, Kasayama S, Jetten AM \& Hirose T 2001 TNF $\alpha$ inhibits 3T3-L1 adipocyte differentiation without downregulating the expression of C/EBP $\beta$ or $\delta$. Endocrine Journal 48 249-253.

Laemmli UK 1970 Cleavage of structural proteins during the assembly of the head of bacteriophage T4. Nature 227 680-685.

Lane MD, Tang QQ \& Jiang MS 1999 Role of the CCAAT enhancer binding proteins (C/EBPs) in adipocyte differentiation. Biochemical and Biophysical Research Communications 266 677-683.

MacDougald OA, Cornelius P, Lin FT, Chen SS \& Lane MD 1994 Glucocorticoids reciprocally regulate expression of the CCAAT/enhancer-binding protein $\alpha$ and $\delta$ genes in 3T3-L1 adipocytes and white adipose tissue. Journal of Biological Chemistry 269 19041-19047.

MacDougald OA, Cornelius P, Liu R \& Lane MD 1995 Insulin regulates transcription of the CCAAT/enhancer binding protein $(\mathrm{C} / \mathrm{EBP}) \alpha, \beta$, and $\delta$ genes in fully-differentiated 3T3-L1 adipocytes. Journal of Biological Chemistry 270 647-654.

Marshall MK, Doerrler W, Feingold KR \& Grunfeld C 1994 Leukemia inhibitory factor induces changes in lipid metabolism in cultured adipocytes. Endocrinology 135 141-147.

Mori M, Yamaguchi K \& Abe K 1989 Purification of a lipoprotein lipase-inhibiting protein produced by a melanoma cell line associated with cancer cachexia. Biochemical and Biophysical Research Communications 160 1085-1092.

Murphy M, Reid K, Hilton DJ \& Bartlett PF 1991 Generation of sensory neurons is stimulated by leukemia inhibitory factor. PNAS 88 3498-3501.

Ohsumi J, Sakakibara S, Yamaguchi J, Miyadai K, Yoshioka S, Fujiwara T, Horikoshi H \& Serizawa N 1994 Troglitazone prevents the inhibitory effects of inflammatory cytokines on insulin-induced adipocyte differentiation in 3T3-L1 cells. Endocrinology 135 2279-2282.

Robinson RC, Grey LM, Staunton D, Vanjelecom H, Vernallis AB, Moreau JF, Stuart DI, Heath JK \& Jones EY 1994 The crystal structure and biological function of leukemia inhibitory factor: implications for receptor binding. Cell 77 1101-1116.

Ruddy MJ, Wong GC, Liu XK, Yamamoto H, Kasayama S, Kirkwood KL \& Gaffen SL 2004 Functional cooperation between interleukin-17 and tumor necrosis factor-alpha is mediated by CCAAT/enhancer binding protein family members. Journal of Biological Chemistry 279 2559-2567.

Schwaninger M, Peterson N, Prinz S, Sallmann S, Neher M \& Spranger M 2000 Adenosine-induced expression of interleukin-6 in astrocytes through protein kinase A and NF-IL-6. Glia 31 51-58. 
Shi H, Tzameli I, Bjorbaek C \& Flier JS 2004 Suppressor of cytokine signaling 3 is a physiological regulator of adipocyte insulin signaling. Journal of Biological Chemistry 279 34733-34740.

Stephens JM \& Pekala PH 1991 Transcriptional repression of the GLUT4 and C/EBP genes in 3T3-L1 adipocytes by tumor necrosis factor-alpha. Journal of Biological Chemistry $\mathbf{2 6 6}$ 21839-21845.

Stephens JM \& Pekala PH 1992 Transcriptional repression of C/EBPo and GLUT4 genes in 3T3-L1 adipocytes by tumor necrosis factor-alpha. Regulation is coordinate and independent of protein synthesis. Journal of Biological Chemistry 267 13580-13584

Stephens JM, Lumpkin SJ \& Fishman JB 1998 Activation of signal transducers and activators of transcription 1 and 3 by leukemia inhibitory factor, oncostatin- $\mathrm{M}$, and interferon- $\gamma$ in adipocytes. Journal of Biological Chemistry 273 31408-31416.

Stewart WC, Morrison RF, Young SL \& Stephens JM 1999 Regulation of signal transducers and activators of transcription (STATs) by effectors of adipogenesis: coordinate regulation of STATs $1,5 \mathrm{~A}$ and $5 \mathrm{~B}$ with peroxisome proliferator-activated receptor- $\gamma$ and C/AAAT enhancer binding protein- $\alpha$. Biochimica et Biophysica Acta 1452 188-196.

Sul HS \& Wang D 1998 Nutritional and hormonal regulation of enzymes in fat synthesis: studies of fatty acid synthase and mitochondrial glycerol-3-phosphate acyltransferase gene transcription. Annual Reviews in Nutrition 18 331-351.

Tanaka T, Yoshida N, Kishimoto T \& Akira S 1997 Defective adipocyte differentiation in mice lacking the $\mathrm{C} / \mathrm{EBP} \beta$ and/or $\mathrm{C} / \mathrm{EBP} \delta$ gene. EMBO Journal 16 7432-7443.
Wagner BJ, Hayes TE, Hoban CJ \& Cochran BH 1990 The SIF binding element confers sis/PDGF inducibility onto the $\mathrm{c}$-fos promoter. EMBO Journal 9 4477-4484.

Williams RL, Hilton DJ, Pease S, Willson TA, Stewart CL, Gearing DP, Wagner EF, Metcalf D, Nicola NA \& Gough NM 1988 Myeloid leukaemia inhibitory factor maintains the developmental potential of embryonic stem cells. Nature 336 684-687.

Wollert KC, Taga T, Saito M, Narazaki M, Kishimoto T, Glembotski CC, Vernallis AB, Heath JK, Pennica D, Wood WI \& Chien KR 1996 Cardiotrophin-1 activates a distinct form of cardiac muscle cell hypertrophy. Assembly of sarcomeric units in series via gp130/leukemia inhibitory factor receptor-dependent pathways. Journal of Biological Chemistry 271 9535-9545.

Yamada T, Tobita K, Osada S, Nishihara T \& Imagawa M 1997 CCAAT/enhancer binding protein $\delta$ gene expression is mediated by APRF/STAT3. Journal of Biological Chemistry 121 731-738.

Zvonic S, Cornelius P, Stewart WJ, Mynatt RL \& Stephens JM 2003 The regulation and activation of ciliary neurotrophic factor signaling proteins in adipocytes. Journal of Biological Chemistry 278 2228-2235.

Zvonic S, Hogan JC, Arbour-Reily P, Mynatt RL \& Stephens JM 2004 Effects of cardiotrophin (CT-1) on adipocytes. Journal of Biological Chemistry 279 47572-47579.

Received in final form 25 February 2005

Accepted 4 March 2005

Made available online as an Accepted Preprint

9 March 2005 